\title{
Rancang Bangun Alat Pendeteksi Kelayakan Air Menggunakan Sensor PH
}

\author{
Fitri Ariska1, Irawan Hadi², Lindawati \\ 1,2,3 Politeknik Negeri Sriwijaya \\ Jl .Srijaya Negara Bukit Besar, Palembang \\ 1fitriariska25@yahoo.com,2irawanhadi@polsri.ac.id,33lindawati@polsri.ac.id
}

\begin{abstract}
One parameter of air quality is the level of turbidity and acidity. For most people, air quality is considered insignificant because it is inappropriate for aesthetics. Good water to be issued according to regulations issued by the government through the Minister of Health of the Republic of Indonesia has a pH value of 6.5 - 8.5 and the maximum turbidity level is 5 NTU (Nephelometric Turbidity Unit). Therefore the author makes a measuring device for acidity in water to facilitate the use of water that will be used by the community. Processing the measurement results is carried out by a $\mathrm{pH}$ sensor which will be processed by the Arduino Uno Microcontroller and produced with output via LCD (Liquid Crystal Display). In this test, the author uses several air samples that have been determined by the government, namely $p H 4, p H 7$ and $p H$ 10. And from several other samples using water that is reasonably suitable for consumption with a $p H$ level of 6.5 and above and can be used as Neutral.
\end{abstract}

Keywords: Analog pH Meter, Arduino Uno, Water Acidity, LCD (Liquid Crystal Display)

\begin{abstract}
Abstrak
Salah satu parameter kualitas air adalah tingkat kekeruhan dan keasaman. Bagi sebagian besar orang, kualitas air dianggap tidak penting karena tidak sekedar estetika. Air yang baik untuk dikonsumsi menurut peraturan yang diterbitkan pemerintah melalui Menteri Kesehatan RI ialah memiliki nilai pH 6,5 - 8,5 dan tingkat kekeruhan maksimal adalah 5 NTU (Nephelometric Turbidity Unit). Oleh karena itu penulis merencanakan membuat alat pengukur kadar keasaman air guna mempermudah mengidentifikasi air yang akan digunakan oleh masyarakat. Pengolahan hasil pengukuran dilakukan oleh sensor $\mathrm{pH}$ yang akan diproses oleh Mikrokontroller Arduino Uno dan dihasilkan dengan keluaran melalui LCD (Liquid Crystal Display). Pada pengujian kali ini, penulis memakai beberapa sample air yang telah ditetapkan oleh pemerintah yaitu $p H 4, p H 7$ dan $p H$ 10. Dan dari beberapa sample lainnya menggunakan air yang cukup layak di konsumsi dengan kadar $p H$ 6,5 keatas dan bisa dikatakan bersifat Netral.
\end{abstract}

Kata kunci: Analog pH Meter, Arduino Uno, Keasaman Air, LCD (Liquid Crystal Display)

\section{PENDAHULUAN}

Air merupakan salah satu kebutuhan pokok dalam kehidupan makhluk di bumi ini. Air digunakan untuk proses metabolisme tubuh baik bagi manusia, hewan maupun makhluk hidup lainnya. Selain itu air juga digunakan oleh manusia untuk memenuhi kebutuhan hidup lainnya misalkan tempat rekreasi, pembangkit energi listrik, transportasi dan pengairan pertanian. Air harus memenuhi beberapa kriteria seperti baik secara kimia, fisika, bakteriologi maupun radioaktif. 
Salah satu cara metode yang umum di masyarakat untuk memenuhi kriteria air baik digunakan untuk memenuhi kebutuhan sehari-hari ialah air tidak berasa, tidak berbau dan tidak berwarna. Selain itu ada beberap kriteria lain yang harus terpenuhi untuk air konsumsi, sehingga kesehatan kita dapat terjaga, yaitu kadar keasaman atau basa biasa disebut $\mathrm{pH}$. Keasaman atau $\mathrm{pH}$ air sangat penting bagi tubuh kita karena bula air yang kita minum memiliki pH yang sangat rendah kebutuhan dalam tubuh kita tidak terpenuhi dengan maksimal. Air minum dengan kualitas yang baik memiliki standar pH 6,5 sampai 8,5 [1]. Untuk mengetahui tingkat kadar $\mathrm{pH}$ dalam air, maka diperlukan pengukuran konsentrasi $\mathrm{pH}$ air. Air minum paling ideal dapat dikonsumsi memiliki kadar netral yaitu pH 7 [2]. Selain itu, air yang tidak mengandung logam berat. Seperti yang diketahui, air yang keruh salah satu ciri air yang tidak sehat. Kekeruhan disebabkan adanya kandungan partikel terlarut dalam air baik yang bersifat organik maupun anorganik. Zat organik berasal dari lapukan tanaman dan hewan, sedangkan zat anorganik berasal dari lapukan batuan dan logam. Dengan adanya zat organik pada air dapat menjadi makanan bakteri sehingga mendukung perkembangannya. Kekeruhan dalam air minum tidak boleh melebihi 5 NTU (Nephelometric Turbididty Unit) [3].

Penulis merencanakan membuat alat pendeteksi kelayakan air menggunakan sensor $\mathrm{pH}$ yang dikur dengan air $\mathrm{pH}$ yang telah ditetapkan. Alat yang penulis rancang ini menggunakan sensor $\mathrm{pH}$ sehingga memiliki keluaran nilai keasaman atau $\mathrm{pH}$ air. Alat yang penulis buat lebih praktis dan mudah dalam penggunaan.

\section{METODOLOGI PENELITIAN}

\subsection{Kerangka Penelitian}

Kerangka penelitian ini membahas tentang diagram secara keseluruhan. Bentuk diagram merupakan bagian terpentig untuk mengetahui tahapan-tahapan yang akan dicapai dalam rancang bangun alat pendeteksi kelayakan air menggunakan mikrokontroller arduino uno dengan notifikasi via LCD (Liquid Crystal Display). Pada tahap perancangan inilah yang menjadi dasar apakah alat yang dibuat sesuai dalam artian beroperasi atau tidak.

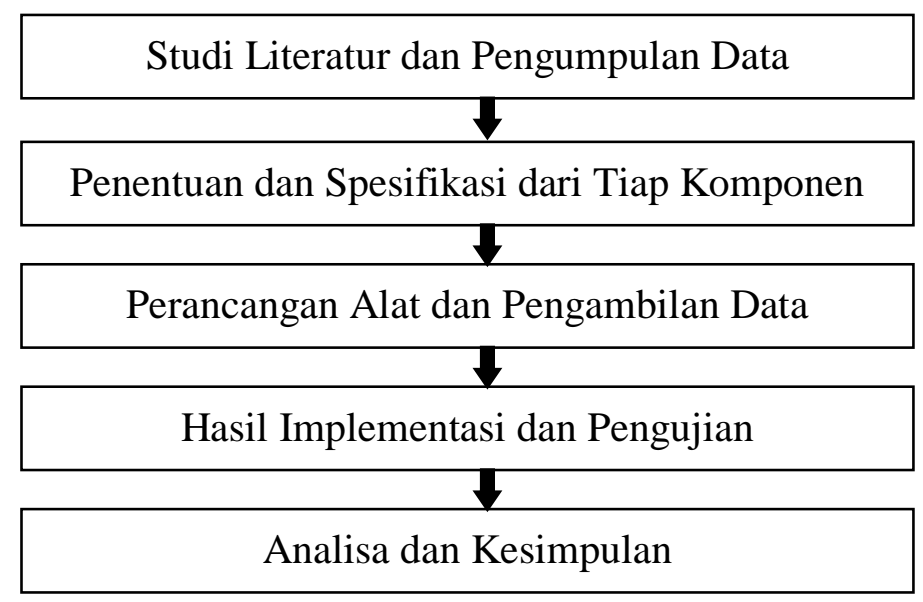

Gambar 1. Kerangka Penelitian 


\subsection{Perancangan Perangkat}

Perancangan merupakan suatu tahap yang penting dalam pembuatan alat. Perancangan dan pembuatan alat ini terdiri dari dua bagian yaitu perancangan hardware dan perintah program. Perancangan sistem diawali dengan diagram blok sistem secara keseluruhan. Blok diagram ialah salah satu bagian terpenting dalam perancangan suatu sistem, karena dari blk diagram rangkaian inilah dapat diketahui cara kerja dari aplikasi secara keseluruhan. Sehingga keseluruhan blok diagram aplikasi tersebut akan menghasilkan suatu sistem yang dapat difungsikan.

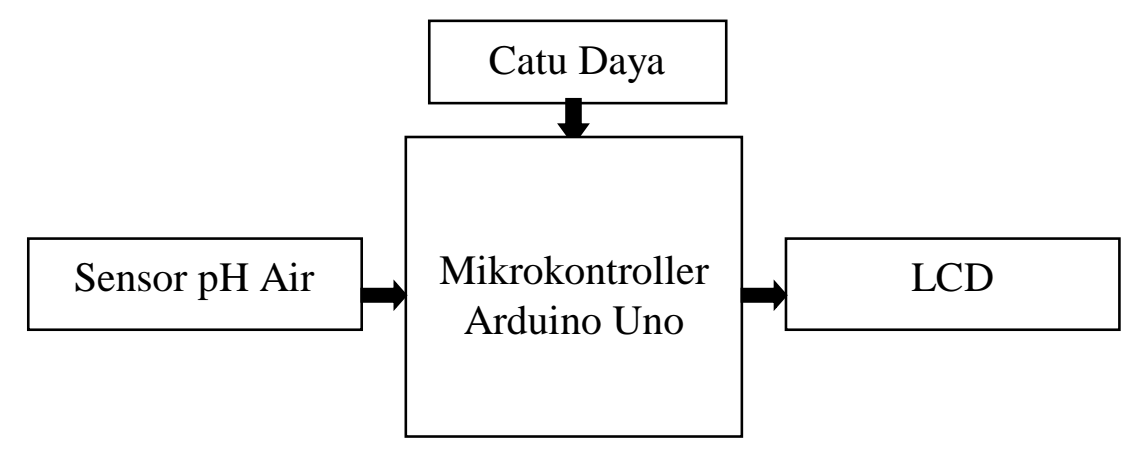

Gambar 2. Blok Diagram Sistem

Pada proses blok diagram diatas, langkah awal perancangan perangkat keras yaitu menghidupkan catu daya atau input sistem yang dirancang pada blok ini terdapat input sensor $\mathrm{pH}$ yang berfungsi sebagai pendeteksi kadar nilai kualitas $\mathrm{pH}$ air dan akan di proses melalui mikrokontroller arduino uno yang telah di setting sebagai pengolah data.

\section{HASIL DAN PEMBAHASAN}

Pada penelitian kali ini menghasilkan sebuah alat yang dapat mendeteksi kelayakan kadar air. Alat ini merupakan alat yang dapat memudahkan masyarakat dalam mendeteksi air yang layak untuk dikonsumsi.

\subsection{Hasil Perancangan Kelayakan Air}

Pada tampilan berupa alat pendeteksi kelayakan air beserta komponennya yang telah dirangkai. Komponen yang digunakan dalam perancangan berupa Mikrokontroller Arduino Uno, Sensor pH Air, LCD (Liquid Crystal Display), PCD Matrik, Jumper secukupnya serta USB sebagai komponen pendukung. Tampilan perancangan alat pendeteksi sebagai berikut : 


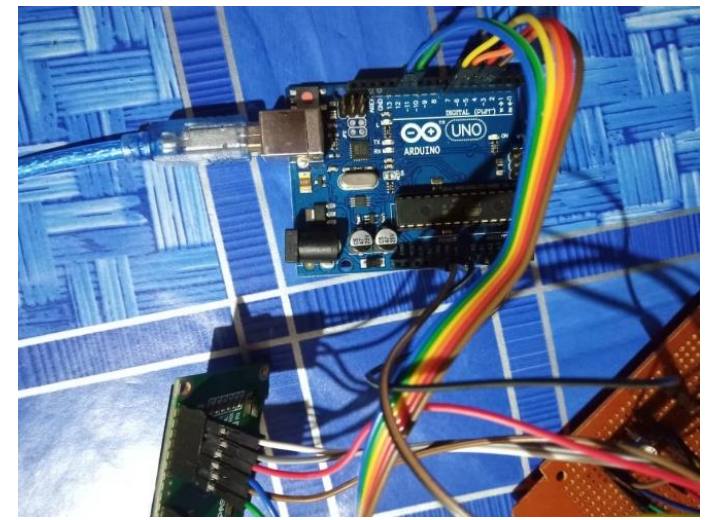

Gambar 3. Tampilan Rangkaian Arduino ke LCD

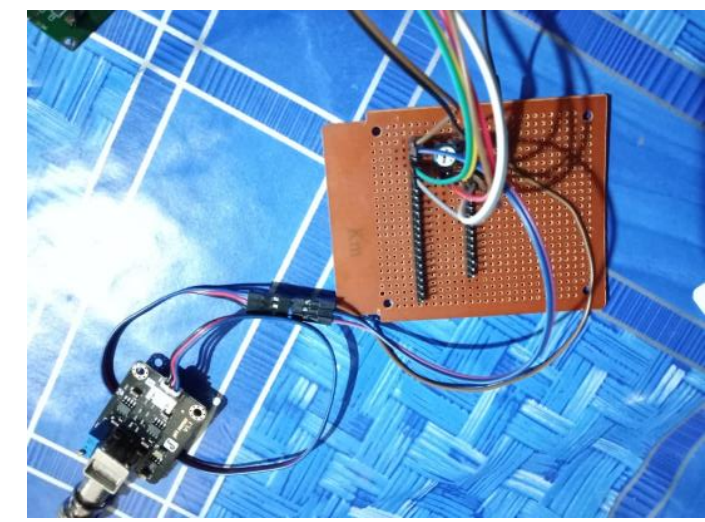

Gambar 4. Tampilan Rangkaian PCB Matriks ke Sensor pH

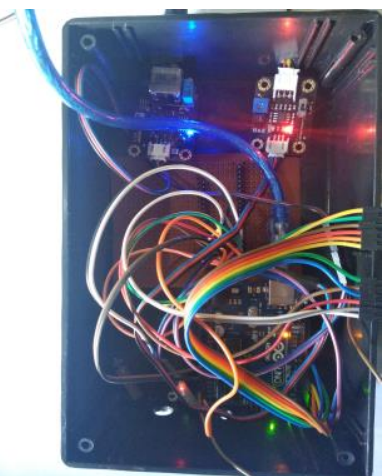

Gambar 5. Tampilan Perancangan Keseluruhan Rangkaian Alat

\subsection{Tampilan Pengujian Alat}

Pada pengujian ini, saat alat digunakan mula-mula akan menampilkan pH meter, saat dimasukkan air cairan uji mulai melakukan pengambilan data. Setelah itu data akan dikirim ke arduino kemudian data keluaran sensor di proses sesuai program dan akan tampil di LCD (Liquid Crystal Display). Tampilan pengujian alat sebagai berikut:

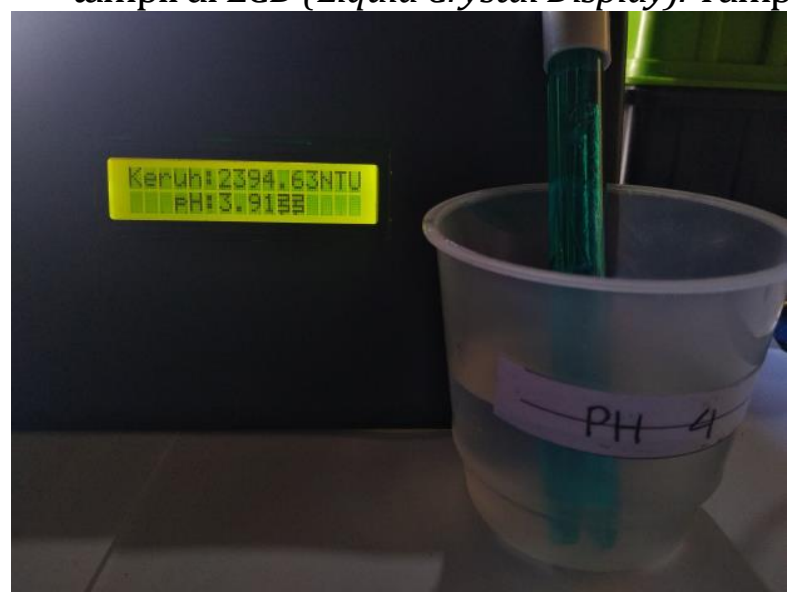

Gambar 6. Tampilan Pengujian dengan Air Buzzer pH 4

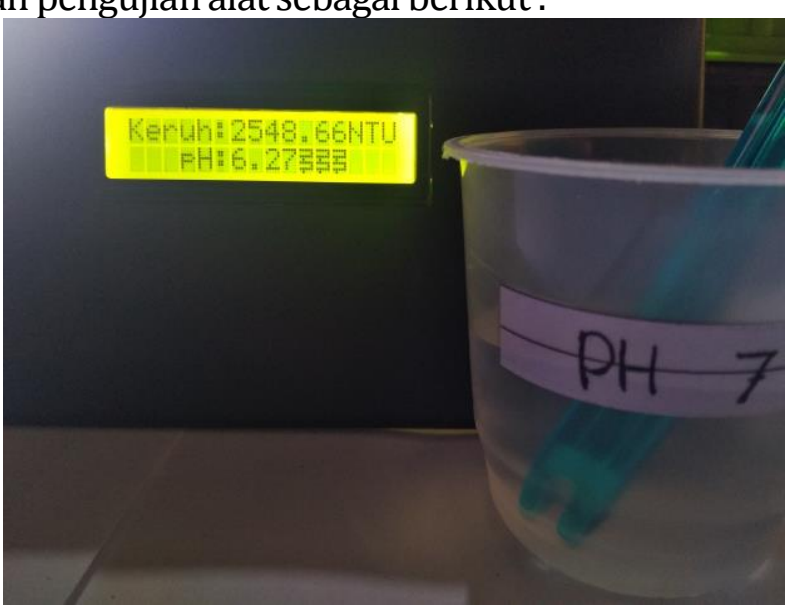

Gambar 7. Tampilan Pengujian dengan Air Buzzer pH 7 


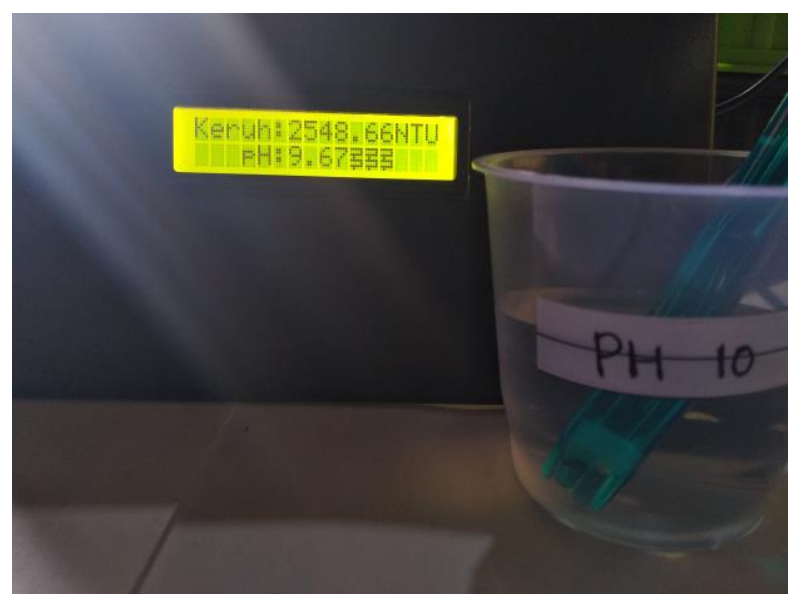

Gambar 8. Tampilan Pengujian dengan Air Buzzer pH 10

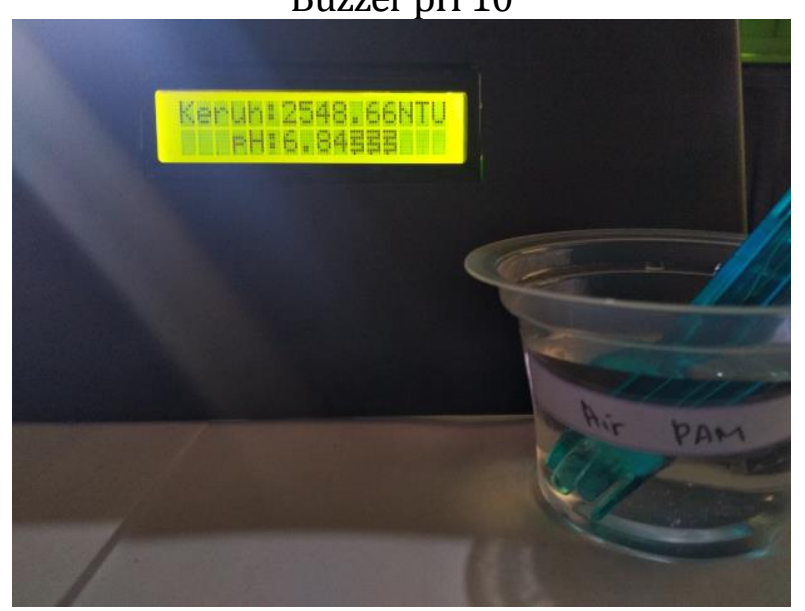

Gambar 10. Tampilan Pengujian Air PDAM

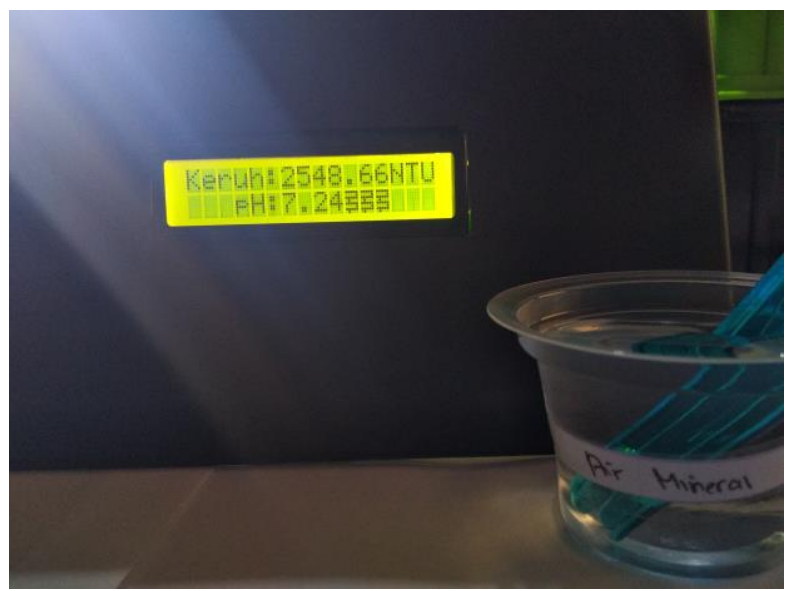

Gambar 9. Tampilan Pengujian Air Mineral "Aqua"

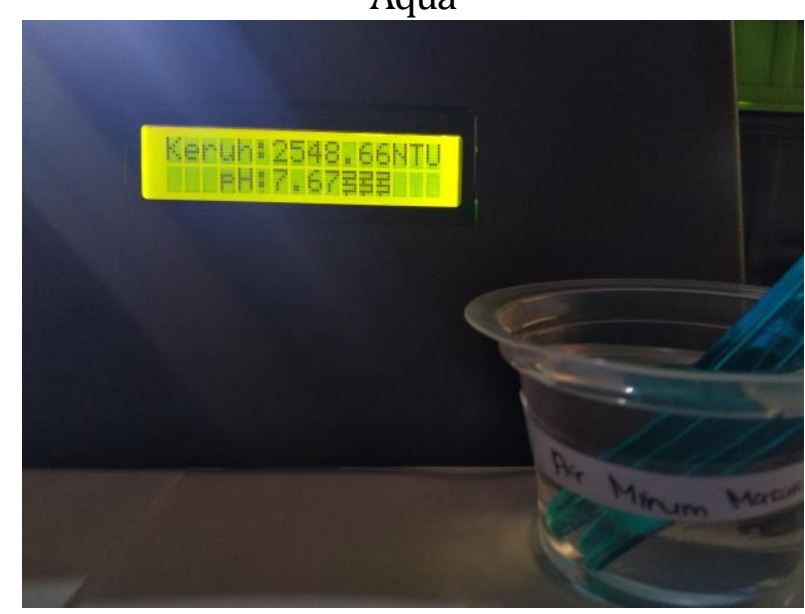

Gambar 11. Tampilan Pengujian Air Minum Masak

Pada pengujian kali ini, dilakukan dengan beberapa sample air. Terutama pada beberapa air yang telah ditetapkan akan diuji dengan alat yang dirancang. Beberapa sample yang ditetapkan yaitu dengan air buzzer $\mathrm{pH}$ 4, pH 7 dan $\mathrm{pH} 10$. Agar mendapatkan hasil yang baik, digunakan sensor yang mudah terbaca pada kadar air tersebut yaitu sensor pH dengan keluaran melalui LCD (Liquid Crystal Display). Pada pengujian pH 4, menghasilkan kadar pH 3,91 yang bersifat Asam. pH 7 menghasilkan kadar pH 6,27 yang bersifat Netral. Sedangkan pH 10 menghasilkan kadar pH 9,67 yang bersifat Basa. Kemudian pada pengujian beberapa sample air lainnya, terdapat hasil yang telah di uji dengan Sensor pH yang menghasilkan Air Mineral ber merk "Aqua" dengan kadar pH 7,24 bersifat Netral. Kemudian dengan Air PDAM menghasilkan kadar pH 6,84 yang bersifat Netral dan dengan Air Minum yang telah di Masak menghasilkan kadar pH 7,67 dengan sifat Netral. Pada pengujian ini, dapat di analisa bahwasannya air yang telah di uji menghasilkan sifat Netral. Artinya, air tersebut layak untuk di konsumsi dan tidak mengandung Asam maupun Logam berat yang mengakibatkan keruhnya air yang akan di minum. 
Jurnal Riset Sistem Informasi Dan Teknik Informatika (JURASIK)

Volume (4) Juli 2019, pp 127-133

ISSN: 2527-5771/EISSN: 2549-7839

http://tunasbangsa.ac.id/ejurnal/index.php/jurasik

\subsection{Tampilan Serial Monitor Arduino}

Pada tampilan yang terdapat di aplikasi arduino tersebut menampilkan beberapa nilai tegangan dan kadar $\mathrm{pH}$ yang masih berubah-ubah. Tampilan ini mendasari untuk dapat mengetahui apakah nilai yang muncul pada LCD sama dengan nilai yang muncul pada apikasi arduino serial monitor. Serial monito juga berfungsi sebagai memantau nilai kadar $\mathrm{pH}$ dan tegangan yang akan diuji. Tampilan serial monitor adalah sebagai berikut.

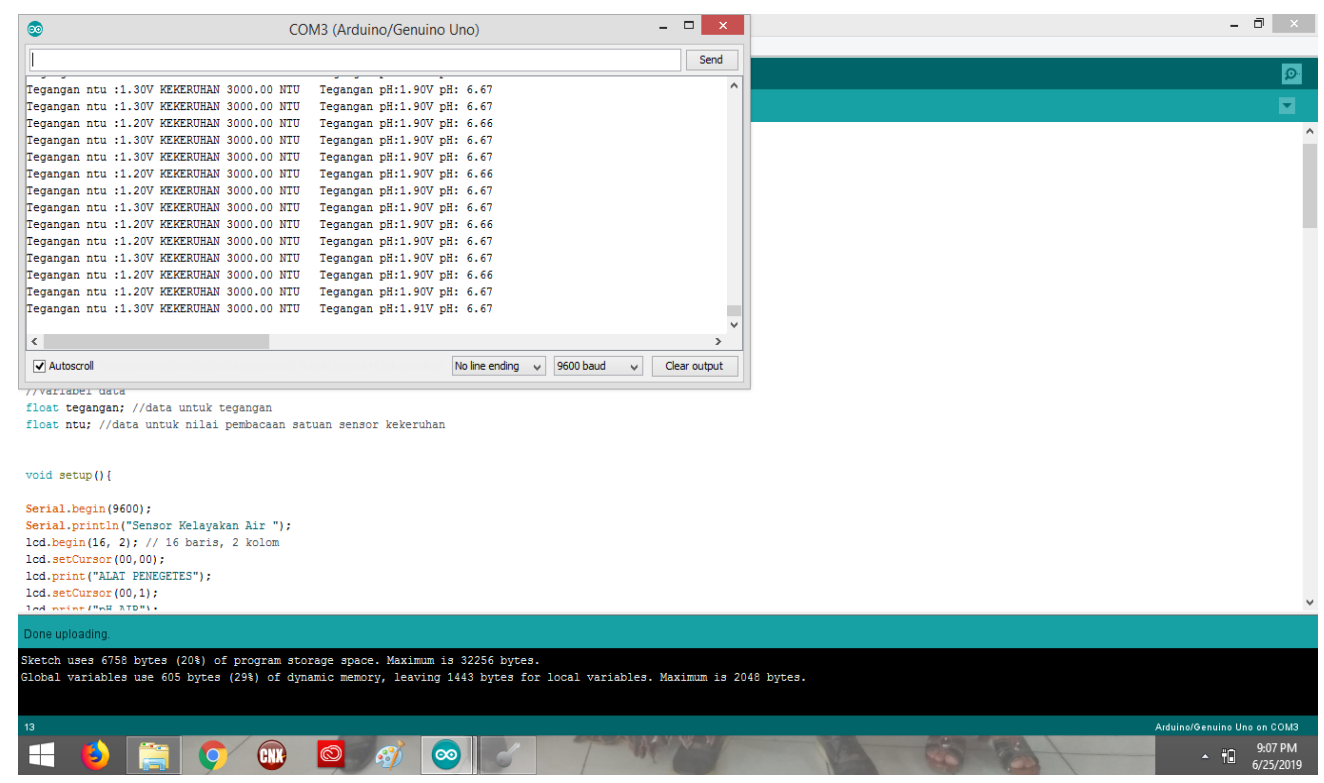

Gambar 12. Tampilan Hasil Pengujian di Aplikasi Arduino

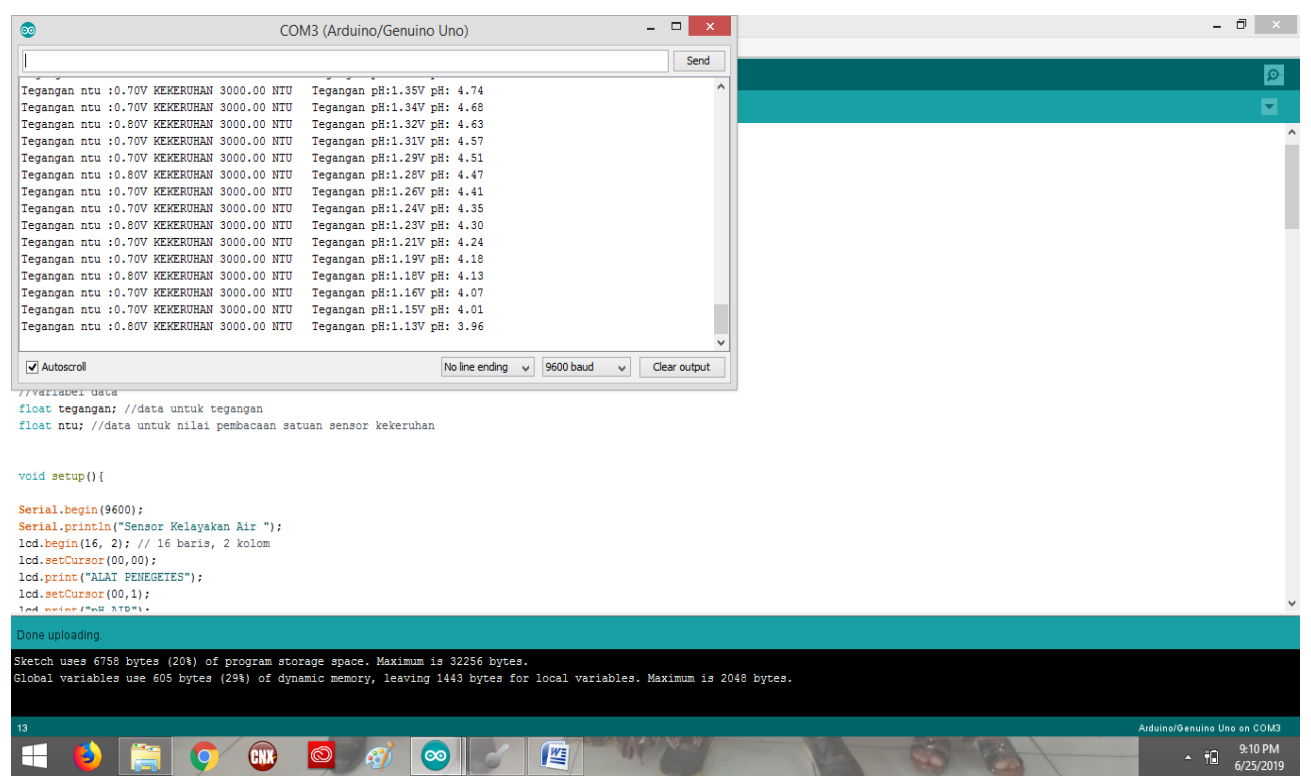

Gambar 13. Tampilan Hasil Pengujian di Aplikasi Arduino 


\subsection{Pengujian Fungsional}

Berikut adalah hasil dari pengujian alat dengan macam-macam sample air :

Tabel 1. Hasil Pengujian Beberapa Sample Air

\begin{tabular}{|c|c|c|c|}
\hline No & Pengujian & Keasaman (pH) & Sifat \\
\hline 1 & Buzzer pH 4 & pH 3,91 & Asam \\
\hline 2 & Buzzer pH 7 & pH 6,27 & Netral \\
\hline 3 & Buzzer pH 10 & pH 9,67 & Basa \\
\hline 4 & Air Mineral “Aqua” & $\mathrm{pH} \mathrm{7,24}$ & Netral \\
\hline 5 & Air PDAM & $\mathrm{pH} \mathrm{6,84}$ & Netral \\
\hline 6 & Air Minum Masak & $\mathrm{pH} \mathrm{7,67}$ & Netral \\
\hline
\end{tabular}

\section{SIMPULAN}

Berdasarkan pengujian untuk mendeteksi kelayakan air ini, dilakukan dengan cara mengevaluasi pengujian menggunakan sensor $\mathrm{pH}$ yang akan di proses melalui mikrokontroller arduino uno dan akan mengeluarkan hasil melalui LCD (Liquid Crystal Display). Pada pengujian ini, terdapat beberapa sample air yang akan diuji salah satunya dengan air buzzer $\mathrm{pH}$ yang telah ditetapkan. Air buzzer $\mathrm{pH}$ yang telah ditetapkan yaitu $\mathrm{pH} 4, \mathrm{pH} 7$ dan $\mathrm{pH}$ 10. Nilai percobaan ini dapat dipengaruhi oleh teknik pengukuran yang kurang baik, suhu sekitar, kebersihan tabung cairan uji. Hal ini dapat mengakibatkan terjadi kesalahan dalam pengukuran. Pada pengukuran keasaman dipengaruhi oleh suhu sekitar dikarenakan keasaman atau $\mathrm{pH}$ air akan berubah sesuai naik dan turunnya suhu air tersebut. jadi pada saat pengukuran suhu ideal nya adalah 25 derajat celcius. Kemudian pada saat pengukuran $\mathrm{pH}$ atau keasaman, sangat dipentingkan bola kaca pada sensor keamanan cairan harus terendam cairan uji agar mendapatkan nilai yang benar.

\section{DAFTAR PUSTAKA}

[1] Peraturan Menteri Kesehatan Republik Indonesia, Tentang Persyaratan Kualitas Air Minum No. 592.MENKES.PER.IV.2019

[2] Hartas,H. 2010. Pendeteksian Keasaman dan Kebasaan pada Pembuburan Kertas dengan Menggunakan pH Meter pada Proses Blecking (Pemutihan). Universitas Sumatera Utara. Medan.

[3] Menteri Kesehatan RI, 2002, Tentang Persyaratan Kualitas Air Minum, NO. 907/MENKES/SK/VII/2002

[4] Ariyansyah Yudi, 2012. "Rancang Bangun Alat Pendeteksi Kadar pH dalam Air dengan Output LCD Berbasis Mikrokontroler", Politeknik Negeri Sriwijaya

[5] Kompasiana.com/klinik/derajat-keasaman, rabu 26 Juni 2019, 11.45 WIB 